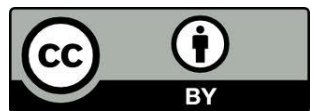

\title{
O SENTIMENTO DE PERTENÇA E SENSÍVEL NOS RITUAIS DA VELA E DO TERÇO ON-LINE ${ }^{I}$
}

\author{
The Feeling of Belonging and Sensitive in Candle and Rosary online rituals o
}

\author{
Carla Valéria da Costa Feitosa \\ Mestra em Comunicação e Linguagens pela Universidade Tuiuti do Paraná \\ Professora de Português Instrumental das Faculdades Batista do Paraná. \\ E-mail:carlavaleria.feitosa@gmail.com
}

RESUMO: Trata do estudo sobre o sentimento de pertença e sensível aplicados aos rituais do terço e da vela virtual afirmando que a cultura ocidental ruma a uma nova religiosidade. Recuero ${ }^{2}$, comentando Ray Oldenburg, adverte que os locais onde os laços de amizades são feitos e alimentados, entre os quais se encontra a igreja, estão fadados ao desaparecimento fazendo com que comunidades virtuais religiosas ofereçam ao público um novo espaço de sociabilidade. Com isso, os rituais já conhecidos como o ato de acender uma vela e rezar o terço estão disponíveis também no mundo virtual e com eles o sentimento de pertencimento a uma comunidade religiosa, já que é desejo dos fiéis manifestarem sua fé juntamente com seus coirmãos. Da mesma forma, o ato de acender uma vela ou rezar o terço via web está repleto de significado na esfera do sensível. Há a necessidade de um ajuste total tanto do usuário quanto da voz gravada disponibilizada pelo site. Tal interação propicia ao usuário sensações de um contato direto com o mundo espiritual. O contato com uma vela acesa, representando pedidos de inúmeros fiéis, e o ato de rezar um terço virtual real, porque a fé é real, pode fazer com que o usuário se sinta convocado por esses rituais, denotando assim um efeito de presença, e contagiado a realizar o mesmo ato de fé.

Palavras chave: Comunicação. Vela e Terço virtuais. Pertença. Sensível.

ABSTRACT: It deals with the study of the sense of belonging and sensitive applied to the virtual rosary and candle rituals claiming that Western culture moves to a new religion. Recuero, commenting Ray Oldenburg, warns that the places where friendships are made and maintained, among them is the church, are doomed to disappear making the religious virtual communities offer to the public a new social space. Thus, the well-known rituals as the act of lighting a candle and praying the rosary are also available in the virtual world and, with them, the feeling of belonging to a religious community, as it is desire of the faithful live their faith along with their brothers. Similarly, the act of lighting a candle or pray the rosary in the web is full of meaning in the sensitive field. There is a special need for a total adjustment of both the user and the recorded voice provided by the site. This interaction provides the user sensations of a direct contact with the spirit world. The contact with a lighted candle, representing the prayers of many followers, and the act of praying a real virtual rosary, because faith is real, it can make the user feel called by these rituals, thus denoting a presence effect, and influenced to perform the same act of faith.

Keywords: Communication. Virtual candle and rosary. Belonging. Sensitive.

\footnotetext{
${ }^{1}$ Parte integrante da dissertação de Mestrado orientada pelo Prof. Dr. Geraldo Pieroni.

2 RECUERO, Raquel da Cunha. Comunidades Virtuais: uma abordagem teórica. Rio Grande do Sul, S.D. Disponível em:< http://www.bocc.ubi.pt/pag/recuero-raquel-comunidades-virtuais.pdf $>$. Acesso em: 26 fev. 2014.
} 


\section{Introdução}

O ritual está presente em todas as religiões proporcionando ao fiel a aproximação com o seu deus e a aceitação pela comunidade religiosa. Este artigo tem por objetivo aplicar o sentimento de pertença e o sensível aos rituais da vela virtual e do terço on-line com base nas reflexões de Vilém Flusser (2002, p. 20), na obra Da Religiosidade, em que afirma que a cultura ocidental caminha rumo a uma nova religiosidade, salientando que novos veículos irão substituir as religiões tradicionais. A questão que se coloca é: de que maneira é proporcionada a experiência do sentimento de pertença e sensível aos usuários dos rituais da vela e do terço on-line?

Wilges (1994) aponta a comunidade e os rituais como elementos constitutivos da religião, salientando que aqueles que seguem uma religião tendem a desejar pertencer à comunidade religiosa e participar dos rituais em conjunto, possível agora também no mundo virtual.

Partindo do hábito como um fazer significante, um modo de agir, os rituais online do terço e da vela serão abordados sob os conceitos de Landowski (2005) e Gumbrecht (2006) no tocante ao sensível. O regime de interação da união será aplicado à utilização do terço; o regime de contaminação (contágio ${ }^{3}$ ) será exemplificado com o ritual da vela, e o ritual do terço embasará a experiência estética ${ }^{4}$ interrompendo o cotidiano.

Os sites www.padremarcelorossi.com.br, www.redevida.com.br, www.velavirtual.com.br e www.aascj.org.br serão utilizados como fonte de estudo para a problemática proposta.

\section{Desenvolvimento}

Flusser (2002, p. 14), na introdução de Da Religiosidade, aponta que a cultura ocidental está em direção a uma nova religiosidade, "a um veículo novo para substituir as religiões tradicionais e abrir campo a nossa religiosidade latente" (FLUSSER, 2002, p. 20). Aponta também que esforços científicos e artísticos estão sendo envidados para que os anseios religiosos sejam supridos, já que "com nossa religiosidade já participamos de uma época vindoura" (FLUSSER, 2002, p. 21). Mas ressalta que essa

\footnotetext{
${ }^{3} \mathrm{Na}$ área médica, o termo contágio é definido como "transmissão de doença de um indivíduo a outro por contato imediato ou mediato" (BORBA, 2004, p. 333). Landowski aplicará o termo à área da comunicação.

${ }^{4}$ Estética, segundo Baumgarten (1993, p. 95), "é a ciência do conhecimento sensitivo".
} 
nova forma de religiosidade é faminta de compromisso, pois

Se as religiões tradicionais são inaceitáveis para essa nova religiosidade, se as religiões exóticas são desvendadas como fugas, e se o desvio da religiosidade para a política, a economia, a tecnologia decepciona, ficamos com a fome religiosa insatisfeita. Invejamos os que a satisfazem na forma tradicional ou nas formas substitutivas, mas simultaneamente sentimos desprezo por eles. Essa mistura de inveja e desprezo, de humildade e blasfêmia, caracteriza a religiosidade insatisfeita. (FLUSSER, 2002, p. 21)

Assim sendo, sentir-se pertencente a uma comunidade religiosa on-line, onde a fé possa ser alimentada e as necessidades espirituais (pedidos, agradecimentos) atendidas, pode minorar a carência dessa nova religiosidade. Recuero ${ }^{5}$, comentando Ray Oldenburg, apresenta a tese de que há três tipos de lugar primordiais na vida: o lar, o trabalho e os outros lugares (onde os laços de amizades seriam feitos e alimentados, como a igreja, a praça, o bar ...). Tais lugares seriam responsáveis pelo sentimento de comunidade, pois são propícios ao lazer e à sociabilidade de um modo geral. Como, em virtude da vida atribulada, tais lugares estão desaparecendo, no entendimento de Oldenburg, o sentimento de comunidade está em falta.

As comunidades virtuais não têm a pretensão de substituir as presenciais, mas têm a intenção de oferecer ao seu público um novo espaço de sociabilidade com estruturas próprias. E como sentir-se pertencente a uma comunidade virtual, para muitos usuários, ainda carregando o ranço de algo abstrato?

Conforme a gramática da Língua Portuguesa, os substantivos, além de outras classificações, podem ser divididos em concretos e abstratos. Cunha e Cintra (2008, p.192) ensinam que "concretos são os substantivos que designam os seres propriamente ditos, isto é, os nomes de pessoas, de lugares, de instituições, de um gênero, de uma espécie ou de um dos seus representantes. " Como exemplo, listam os seguintes substantivos: homem, cidade, Maria, animal. Substantivos abstratos são aqueles "que designam noções, ações, estados e qualidades, considerados como seres. " E enumeram alguns como exemplo: justiça, colheita, limpeza, verdade.

Alguns, erroneamente, classificam de abstrato aquilo que não pode ser tocado.

\footnotetext{
${ }^{5}$ RECUERO, Raquel da Cunha. Comunidades Virtuais: uma abordagem teórica. Rio Grande do Sul, S.D. Disponível em:< http://www.bocc.ubi.pt/pag/recuero-raquel-comunidades-virtuais.pdf>. Acesso em: 26 fev. 2014.
} 
Fábio Alves ${ }^{6}$ relata sua experiência enquanto aluno:

\begin{abstract}
Quando eu estava no primário, hoje rebatizado de fundamental, a professora ensinou que substantivo abstrato era tudo aquilo que não se podia ver ou pegar. Deus, nuvem, fantasma, tudo isso seria substantivo abstrato. Bem se vê que ela nada entendia de gramática da língua portuguesa e este ensinamento errado me acompanhou por longos anos até que eu revi a gramática e vi meu erro.
\end{abstract}

É possível fazer um paralelo entre o que a Academia ensina sobre classes de palavras e o que Flusser (2002, p. 147) apresenta como classes de signos e significados. Para o teórico da comunicação, o conceito concreto possui apenas um representante, e o conceito abstrato tem vários. Exemplificando: só houve um presidente Fernando Henrique Cardoso na República Federativa do Brasil, é um conceito concreto; mas o Brasil já teve vários presidentes em sua República, é um conceito abstrato. "O conceito concreto é, portanto, uma classe de um único membro, e o abstrato tem vários membros que podem ser, por sua vez, classes. " (FLUSSER, 2002, p. 147-148).

Segundo o conceito da gramática da língua portuguesa, a comunidade virtual é um substantivo concreto, já que é algo que existe por si só ou se apresenta em nossa imaginação como se existisse por si só. Para a professora equivocada do relato acima, a comunidade virtual é um substantivo abstrato, já que não pode ser tocada por ser virtual. Flusser, certamente, a conceituaria de duas maneiras distintas: a comunidade virtual Rede Eletro-Cristo com Maria, do Padre Marcelo Rossi, é concreta em virtude de ter apenas um representante; as demais comunidades virtuais são abstratas por terem vários representantes.

A concretude da comunidade virtual Rede Eletro-Cristo com Maria vai além da sua representatividade única. É concreta porque está disponível a qualquer momento, basta acessar o site; é concreta porque as necessidades daqueles que a procuram para acender uma vela ou rezar o terço são concretas, porque a fé do usuário é concreta. Ou seja, não importa, efetivamente, se a comunidade é ou não concreta, mas sim o valor simbólico, a experiência de fé efetiva que ela suscita em quem acredita. A experiência aciona, mobiliza essa fé e estimula ou demanda uma espécie de consenso orquestrado via dispositivo, no caso, não mais o dispositivo da comunidade física, mas da comunidade midiática, virtualizada, ancorada na crença.

\footnotetext{
6 ALVES, Fábio. Substantivos Concretos e Abstratos. Rio Grande do Sul, 2013. Disponível em:< http://gramaticaemvideo.com.br/?page_id=1930>. Acesso em: 26 fev. 2014.
} 
Entre os elementos constitutivos da religião, Wilges (1994, p. 16) cita a Comunidade, enfatizando que: “A religião tende a formar comunidade. Quem está convencido de uma crença sente-se irresistivelmente atraído para os seus coirmãos e quer manifestar a sua fé junto com eles." E é dessa forma que tem ocorrido nas comunidades virtuais, por meio dos rituais ali disponibilizados, o usuário se sente participante daquela comunidade e em comunhão com ela. "Através deles (dos ritos) a comunidade se une." (WILGES, 1994, p.16) A seguir, um agradecimento deixado no site da Associação Apostolado do Sagrado Coração de Jesus ${ }^{7}$ por MSF, que, sentindo-se pertencente à Associação, sabe que há um grupo que intercede por ela.

(...) Muito obrigada à Associação por colocar pessoas rezando por nossos pedidos. Em agradecimento estou fazendo uma novena para as pessoas que insrevem (sic) seus pedidos no site. Muito obrigada Sagrado Coração de Jesus.

É costume das comunidades físicas terem um ritual de admissão de um novo membro àquele grupo. Nas comunidades religiosas cristãs, muitas vezes, o fiel precisa passar por um grupo de estudos e/ou pelo batismo para ter seu nome arrolado como membro. A comunidade virtual também tem o seu ritual. O usuário precisa informar seus dados e, ao receber uma mensagem de confirmação, clicar no link enviado para que faça parte do grupo. Dessa forma, a cada vez que acessar o grupo com o e-mail cadastrado, será reconhecido como pertencente à comunidade e poderá navegar por ciberespaços disponibilizados somente aos membros.

Mas a Comunidade não fica a mercê do desejo do usuário voltar ao site, segundo Bellotti (2004), "o sentimento de pertença precisa ser renovado todo dia, a cada culto, a cada oração, a cada confronto com aquele que possui uma crença diferente." Visando alimentar o sentimento de pertença, a Rede Eletro-Cristo com Maria encaminha diariamente aos usuários cadastrados no site do Pe. Marcelo Rossi uma mensagem eletrônica ${ }^{8}$ :

\footnotetext{
7 MSF. Graças Alcançadas. São Paulo; 2012. Disponível em:< http://www.aascj.org.br/home/gracasalcancadas/comment-page-15/\#comments> Acesso em: 17 mar. 2014.

${ }^{8}$ ROSSI, Padre Marcelo. Terço Bizantino. [mensagem pessoal]. Mensagem recebida por carlavaleria.feitosa@ig.com.br 21 fev.2014.
} 
Evangelize seus amigos, seus familiares através dos seus contatos, das redes sociais: Facebook, Twitter, Orkut, Linkedin, Instagram. Junte-se a nós, faça parte da Rede Eletro-Cristo com Maria, compartilhe bênçãos.

TERÇO BIZANTINO - ORANDO PELAS PESSOAS AGITADAS

Terço Bizantino, uma oração simples que chega ao céu. (VIGÉSIMO SEXTO DIA )

Terço Bizantino em Vídeo. Assistir

VC olha, VC lê e Ele fala com VC!

Espalhe e compartilhe a boa nova!

Clique Aqui

Junte-se a nossa Família na Rede Eletro-Cristo com MARIA. CADASTRE-SE GRATUITAMENTE! Não se esqueça de adicionar o site www.padremarcelorossi.com.br em sua lista de contatos, amigos, lista de confiança para que o Anti-Spam não bloqueie as mensagens e orações enviadas diariamente. Vamos formar novos amigos na Rede Eletro-Cristo com MARIA. DIVULGUE !!!

EVANGELIZAR = FELICIDADE, SEJA FELIZ, EVANGELIZE !!! Ouça a Benção do Padre Marcelo Rossi. Ouvir Amados, Abençoe-vos o Deus Todo-Poderoso o Pai $\dagger$ e o Filho e o Espírito Santo. Amém! Paz e bem! Fique com Deus, e Evangelizem!

Padre Marcelo Rossi

É claro o objetivo da mensagem eletrônica em fazer o membro cadastrado sentirse pertencente a uma comunidade e responsável pelo crescimento dela. Palavras de incentivo a que compartilhe com os amigos pelos meios eletrônicos e que até faça novos amigos na Rede são incisivas. E se, por algum motivo, o site deixa de enviar regularmente as mensagens, o membro, que já se sente pertencente ao grupo, sente-se no direito de requerer o retorno dos contatos. Segue exemplo retirado do site da Associação Apostolado do Sagrado Coração de Jesus ${ }^{9}$ escrito por VLP:

sou sócia do meu sagrado coração de jesus , sempre recebia email, mais faz tempo que não recebo o que esta acontesendo (sic), esqueceram de mim ?

O site www.velavirtual.com.br faz o usuário sentir-se pertencente à comunidade virtual enviando mensagens eletrônicas regularmente e informando, na primeira página, que o pedido feito de forma virtual será inscrito no Livro de Orações da Associação Apostolado Sagrado Coração de Jesus, e as intenções serão lembradas nas Missas, nos Grupos de Orações, nos Conventos e Casas Religiosas que participam do apostolado durante os 7 dias que a vela estiver acesa. Além disso, após acender a vela, o usuário é direcionado para uma página onde há o link "área reservada aos membros do Grupo Famílias do Sagrado Coração de Jesus" em que é possível um novo cadastro, desta vez

\footnotetext{
9 VLP. Graças Alcançadas. São Paulo, 2012. Disponível em:< http://www.aascj.org.br/home/gracasalcancadas/comment-page-8/\#comments> Acesso em: 17 mar.2014.
} 
para fazer parte específica desse Grupo e ter o nome em mais de 60 missas. Ao tornar-se membro do Grupo, o usuário receberá alguns privilégios, como: ter acesso ao calendário de missas e orações e incluir seus pedidos, ter o nome lembrado na Missa dos Aniversariantes e receber os boletins do Apostolado.

A vela e o terço utilizados em rituais católicos têm em si simbologias e significados. Como transpor essa aura de poder, esse milagre em potência para o ciberespaço? É possível à vela on-line e ao terço vritual carregarem esse mesmo simbolismo, serem reais?

Flusser (2002, p. 13) argumenta que "real é aquilo no qual acreditamos." Portanto, o real não está colado ao objeto, mas à fé de quem o observa. Até pouco tempo atrás nos referíamos a dois mundos: o real e o virtual. $\mathrm{O}$ que nos remetia à conclusão de que o que era virtual não era real. Hoje se perdeu a noção dessa diferença, tudo é real, inclusive o que é virtual. Sobre isso, pode-se utilizar o que diz Flusser (2002, p. 13): “... nossa situação é caracterizada pela sensação do irreal e pela procura de um senso novo de realidade. Portanto, pela procura de uma nova religiosidade." Logo, se uma vela on-line é escolhida para ser o veículo de súplica ou gratidão, ela é real. A graça pretendida não está na vela ou no terço, mas no fato de ser desejada. Assim, a vela e o terço simbolizam o desejo em potência, é o real em potência, é o vir a ser que depende apenas do quanto se acredita e talvez por isso esteja sendo cada vez mais valorizado.

A realização de rituais é habitual na vida de religiosos. Confessar-se, acender uma vela, rezar o terço, participar da eucaristia são ações usuais para aqueles que praticam o catolicismo. Com a disponibilidade de algumas dessas atividades on-line, não é difícil supor que alguns religiosos tenham migrado a ação de fazer do mundo físico para os sites religiosos. Outros, talvez, não tivessem o hábito de ir à igreja, rezar o terço e acender a vela, mas com a facilidade de acesso à web adotaram como hábito tais rituais. Oliveira ${ }^{10}$, comentando Eric Landowski ${ }^{11}$, afirma que:

O hábito é uma prática significante de um fazer, de um modo de agir, que produz um tipo específico de contato entre o sujeito e o que ele faz. A ação

\footnotetext{
${ }^{10}$ OLIVEIRA, Ana Cláuda Mei Alves de. A leitura do jornal como experiência sensível. São Paulo, 2004. Disponível em: < http://www.pucsp.br/cps/pt-br/arquivo/Biblio-AnaClaudia3.pdf>. Acesso em: 06 mar. 2014.

${ }^{11}$ LANDOWSKI, Eric. Passions sans nom. Paris, P.U.F. 2004.
} 
de fazer o que já se conhece estrutura-se como um hábito quando aquele que a realiza deliberadamente a investe do propósito de obter com essa retomada as dimensões sensíveis que tal ação lhe aporta.

Assim, o ato de acender uma vela ou rezar o terço via web está repleto de significado na esfera do sensível. Provavelmente, os rituais virtuais não tenham a mesma aura conceituada por Benjamin (apud TALON-HUGON, 2009, p. 76) como "a única aparição de um longínquo, por mais próxima que possa estar”. Mas, certamente, para o usuário com fé não importa se o ritual é virtual, seu pedido (ou sua gratidão) será ouvido por Deus. Assim como um casal que dança precisa de um ajuste dos corpos e do ritmo para que o fazer junto seja harmonioso, o usuário que reza o terço on-line também precisa se ajustar ao ritmo da voz gravada, à cadência das orações e ao tempo proposto para o ritual. Mas não é só o usuário que precisa se amoldar. Ao elaborar o ritual virtual, há a preocupação em disponibilizar algo que seja adequado a todos os usuários. A voz de quem reza precisa ser suave, clara, contrita; a figura do terço e o que irá salientar a conta que está sendo rezada também precisam ser ajustados ao mundo virtual, mas ao mesmo tempo retratar com perfeição o ritual já conhecido pelos religiosos. Conforme Landowski (2005, p.19), esse ato é conceituado de união, "no qual os actantes entram estesicamente em contato dinâmico... sua co-presença interativa que será reconhecida como apta a fazer sentido, no ato, e a criar valores novos." Tal interação é abrigada na ordem do sensível na medida em que propicia ao usuário sensações de um contato direto com o mundo espiritual. De Gumbrecht (2006, p. 57) extrai-se o conceito de crises que uma experiência estética pode proporcionar no cotidiano. Tomando o exemplo das cadeiras de Bauhaus ${ }^{12}$, em que o "cada vez mais" é o ponto desencadeador da interrupção do cotidiano, transpõe-se a análise para o terço visto como calmante na fala do Pe. Joãozinho (apud FAUSTO NETO, 2006):

Sono é alimento. Não dá para passar três dias sem comer, não dá pra passar três noites sem dormir (...) Eu sempre digo, reze o terço. Rezar o terço é um calmante. Vai rezando, rezando ... E na maioria das vezes resolve, a pessoa dorme.

No enunciado do Padre, quanto mais o fiel rezar, mais existe a possibilidade de desencadear uma interrupção no cotidiano e resolver o problema do seu interlocutor.

\footnotetext{
12 Bauhaus - escola interdisciplinar que visava à interação entre as artes plásticas e o desenho industrial. Suas cadeiras demonstram a preocupação com o conforto e a postura que uma pessoa toma ao sentar-se.
} 
Em Landowski, também se pode realizar a leitura do contágio e aplicar seu conceito aos rituais realizados on-line. Com o teórico, o termo ganhou um significado diferente do que lhe foi conferido na área médica. Exemplificando com o ato de gargalhar, o autor explica que:

Devido ao simples fato de que ver rir tende, por si mesmo, a fazer rir. Tudo acontece então como se houvesse uma eficácia performática da co-presença, como se nossa percepção das manifestações somáticas dos estados vividos pelo outro tivesse o efeito de fazermos contrair os mesmos estados. (LANDOWSKI, 2005, p. 21)

Ou seja, o estado hilário de alguém próximo pode desencadear o mesmo estado nas pessoas que estão ao redor. $\mathrm{O}$ ato de fé de um usuário que acessa um site, abre seu coração, escreve seu pedido e acende uma vela pode desencadear o mesmo processo em um outro usuário. Ao se deparar com uma página repleta de velas acesas representando a necessidade de inúmeras pessoas que acreditam que terão seus problemas resolvidos, um usuário pode ser chamado, convocado por uma vela, denotando assim um efeito de presença, e sentir-se contagiado a realizar o mesmo ato de fé.

\section{Considerações finais}

É inegável que o mundo ocidental vive à procura de novos rumos para a sua religiosidade. Com a proliferação dos sites religiosos e a disponibilização dos rituais no mundo virtual, a ação de fazer do mundo físico estendeu-se ao ciberespaço. A questão norteadora deste estudo, a saber: de que maneira é proporcionada a experiência do sentimento de pertença e sensível aos usuários dos rituais da vela e do terço on-line?, propiciou uma reflexão sobre a experiência estética que o usuário tem experimentado através dos rituais da vela e do terço on-line.

Em Gumbrecht (2006, p.55), constata-se que tal prática pode ser presenciada partindo de uma interrupção do cotidiano. Não é difícil imaginar um usuário navegando em um site religioso e, subitamente, sentir-se convocado pelas inúmeras velas acesas a participar do mesmo ritual e o faça com fé, contrição e esperança de ter seu pedido atendido. Gumbrecht (2006, p. 57), da mesma forma, inclui a adaptação máxima dos objetos à função viabilizando cada vez mais a sua utilização como indicativo dessa vivência. Ou seja, um usuário, após um período de adaptação ao tempo despendido, à ambiência do espaço virtual e à voz gravada que reza o terço, pode, cada vez mais, 
utilizar-se desse ritual virtual e passar pela experiência do ato de união descrita por Landowski (2005, p.19).

Também em Landowski (2005, p.21), constata-se a experiência do contágio, quando um usuário ao se deparar com inúmeras velas acesas se sente contagiado pelo ato de fé e realiza o mesmo ritual.

O olhar estético sobre os rituais on-line poderia ainda se apoderar do conceito de Greimas no tocante a "espera esperada do inesperado", ou de Quéré com relação ao caráter impessoal da experiência. Porém o assunto é demasiadamente vasto, interessante e profundo e não seria producente abordá-lo de outra forma senão profunda. Dessa maneira, como não é objetivo deste artigo explorar todo o assunto, abre-se um caminho para uma outra pesquisa.

\section{Referenciais}

ALVES, Fábio. Substantivos Concretos e Abstratos. Rio Grande do Sul, 2013. Disponível em:< http://gramaticaemvideo.com.br/?page_id=1930>. Acesso em: 26 fev. 2014.

BAUMGARTEN, Alexander Gottlieb. Estética: a lógica da arte e do poema. Petrópolis: Vozes, 1993.

BELLOTTI, Karina Kosicki. Mídia, Religião e História Cultural. Revista de Estudos da Religião, 2004. Disponível em: WWW.pucp.br/rever4_2004/p_bellotti.pdf. Acesso em: 27 jun. 2013.

BORBA, Francisco da Silva. Dicionário UNESP do Português Contemporâneo. UNESP: São Paulo, 2004.

CUNHA, Celso \& CINTRA, Luís F. Lindley. Nova gramática do português contemporâneo. 5. Ed., Rio de Janeiro: Lexiton, 2008.

FAUSTO NETO, Antônio. Dispositivos de tele-cura e contratos da salvação. "Você que disse que Deus fazia isso só antigamente, Deus continua fazendo hoje pela televisão" (Missa de Cura e de Libertação, TV Canção Nova, 16.01.05). In: UNIrevista, vol. $3, n^{\circ} 1$, julho, 2006, São Leopoldo: Unisinos.

FLUSSER, Vilém. Da Religiosidade: a literatura e o senso de realidade. São Paulo: Escrituras Editora, 2002.

GUMBRECHT, Hans Ulrich. Pequenas crises: experiência estética nos mundos cotidianos. In: GUIMARÃES, César; LEAL, Bruno; MENDONÇA, Carlos. Comunicação experiência estética. Belo Horizonte: Editora UFMG, 2006. p.50-63. 
LANDOWSKI, Eric. Aquém ou além das estratégias, a presença contagiosa. São Paulo: Edições CPS, 2005.

Passions sans nom. Paris, P.U.F. 2004.

MSF. Graças Alcançadas. São Paulo; 2012. Disponível em:< http://www.aascj.org.br/home/gracas-alcancadas/comment-page-15/\#comments> Acesso em: 17 mar. 2014.

OLIVEIRA, Ana Cláuda Mei Alves de. A leitura do jornal como experiência sensível. São Paulo, 2004. Disponível em: < http://www.pucsp.br/cps/pt-br/arquivo/BiblioAnaClaudia3.pdf>. Acesso em: 06 mar. 2014.

RECUERO, Raquel da Cunha. Comunidades Virtuais: uma abordagem teórica. Rio Grande do Sul, S.D. Disponível em:< http://www.bocc.ubi.pt/pag/recuero-raquelcomunidades-virtuais.pdf $>$. Acesso em: 26 fev. 2014.

ROSSI, Padre Marcelo.Terço Bizantino. [mensagem pessoal]. Mensagem recebida por carlavaleria.feitosa@ig.com.br 21fev.2014.

TALON-HUGON, Carole. A estética: história e teorias. Lisboa: Texto \& Grafia, 2009.

VLP. Graças Alcançadas. São Paulo, 2012. Disponível em:< http://www.aascj.org.br/home/gracas-alcancadas/comment-page-8/\#comments> Acesso em: 17 mar.2014.

WILGES, Irineu. Cultura Religiosa: as religiões no mundo. Petrópolis, RJ: Vozes, 1994.

Recebido: $11 / 05 / 2016$

Received: 05/11/2016

Aprovado: $30 / 05 / 2016$

Approved: 05/30/2016 